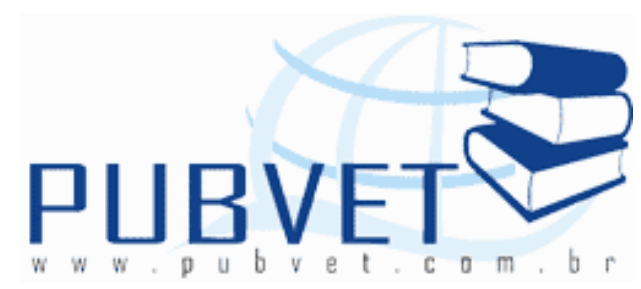

PUBVET, Publicações em Medicina Veterinária e Zootecnia.

\title{
Níveis séricos de uréia e creatinina em cães naturalmente infectados por Leishmania chagasi
}

\begin{abstract}
Marcus Vinicius Caetano de Sousa ${ }^{1}$; Igor Paula de Castro ${ }^{1}$; Geórgia Modé Magalhães²; Antônio Vicente Mundim³; Nicolle Pereira Soares ${ }^{4}$; Pablo Gomes Noleto ${ }^{1}$; Ana Cláudia Borges ${ }^{5}$; Jean Ezequiel Limongi ${ }^{6}$, Alessandra Aparecida Medeiros $^{7}$
\end{abstract}

${ }^{1}$ Mestrando em Ciência Animal - Laboratório de Patologia Animal - Faculdade de Medicina Veterinária (FAMEV), Universidade Federal de Uberlândia (UFU), Uberlândia, MG, Brasil;

*sousa.marcusviniciusmvet@hotmail.com

${ }^{2}$ Professora Mestre - Laboratório de Patologia Animal - FAMEV - UFU;

${ }^{3}$ Professor Doutor - Laboratório de Patologia Clínica Veterinária - FAMEV - UFU;

${ }^{4}$ Aluna de Iniciação Científica- Laboratório de Patologia Animal - FAMEV - UFU;

${ }^{5}$ Médica Veterinária - Centro de Controle de Zoonoses - Uberlândia- MG

${ }^{6}$ Biólogo - Centro de Controle de Zoonoses - Uberlândia- MG

${ }^{7}$ Professora Doutora, Laboratório de Patologia Animal - FAMEV - UFU;

\section{Resumo}

A Leishmaniose Visceral é considerada pela Organização Mundial de Saúde como uma das seis endemias prioritárias no mundo, sendo que os cães atuam como reservatórios naturais do parasito. Um dos órgãos acometidos que não faz parte do sistema fagocítico mononuclear são os rins, causando nefropatias 
e portando merecendo atenção especial. Os valores bioquímicos de uréia e creatinina são utilizados para avaliar se existem alterações renais. Objetivouse com este estudo avaliar se há alterações nos valores séricos de uréia e creatinina de cães naturalmente infectados com Leishmania chagasi apresentando diferentes sintomatologias para melhor entender a patogenia da doença. Foram utilizados 44 cães cedidos pelo Centro de Controle de Zoonoses de Uberlândia- MG. Os animais foram examinados clinicamente antes da eutanásia, assim como foi coletado o sangue por venopunção jugular para mensuração das concentrações séricas de uréia e creatinina. Os cães foram classificados em assintomáticos $(n=4)$, oligossintomáticos $(n=23)$ e sintomáticos $(n=17)$. Não houve diferença estatística entre as médias dos níveis de uréia e creatinina nos cães com diferentes sintomatologias clínicas.

Palavras-chave: Azotemia, Leishmaniose, Rim.

\section{Seric urea and creatinine levels in dogs naturally infected by Leishmania chagasi}

\section{Abstract}

The Leishmaniasis is considered by the World Health Organisation as one of six priority endemic diseases in the world, and that dogs act as natural reservoirs of the parasite. One of the affected organs that is not part of the mononuclear phagocytic system are the kidneys, causing nefropathy and therefore to require special attention. The biochemical values of urea and creatinine are used to evaluate whether there are changes in the kidneys. The objective of this study was to evaluate whether changes in serum urea and creatinine in dogs naturally infected with Leishmania chagasi showing different symptomatology to better understand the pathogenesis of the disease. We used 44 dogs donated by the Zoonosis Control Center of Uberlândia-MG. The animals were examined clinically prior to euthanasia, and blood was collected by jugular venipuncture for the measurement of serum urea and creatinine. The dogs were classified as asymptomatic $(n=4)$, oligossymptomatic $(n=23)$ 
SOUSA, M.V.C. et al. Níveis séricos de uréia e creatinina em cães naturalmente infectados por Leishmania chagasi. PUBVET, Londrina, V. 5, N. 12, Ed. 159, Art. 1078, 2011.

and symptomatic $(n=17)$. There was no statistical difference between the mean levels of urea and creatinine in dogs with different clinical symptomatology.

Keywords: azotemia, Leishmaniasis, kidney.

\section{INTRODUÇÃO}

A leishmaniose visceral (LV) é uma zoonose causada pela infecção com Leishmania chagasi, transmitida por vetores do gênero Lutzomyia (DA SILVA, et al., 2009). É considerada pela Organização Mundial de Saúde uma das endemias mundiais mais importantes e no Brasil atinge 19 estados tendo uma média anual de 3.000 casos, sendo que 50\% ocorrem em crianças de 0 a 9 anos de idade causando altas taxas de morbidade e mortalidade (BRASIL, 2003).

A Leishmaniose Visceral Canina (LVC) é uma doença emergente no Brasil em áreas urbanas, sendo que os cães são os principais reservatórios do parasita representando um importante foco no controle da doença (OLIVEIRA, et al., 2009; DA SILVA, et al., 2009). A peri-urbanização e a urbanização estão associadas ao aumento do número de casos e a expansão territorial em todo o país, inclusive com surtos em algumas capitais como Belo Horizonte (BRASIL, 2003).

As leishmanias quando são inoculadas na pele do hospedeiro pelos flebótomos, invadem os macrófagos e neles se multiplicam (SILVA, 2007), desencadeando alguns sinais clínicos, dentre eles estão hepatoesplenomegalia, linfadenopatia, lesões cutâneas, ceratoconjuntivite, alopecia, apatia, onicogrifose, anorexia, grave perda de peso (REIS et al., 2006) glomerulonefrite membranoproliferativa e nefrite intersticial (Lopez et al., 1996). Os animais assintomáticos representam grande problema para a saúde pública, e dificultam à deteç̧ão da doença e a adoção de medidas adequadas de controle (MACHADO, HOFFMANN, LANGONI, 2007). 
Os rins são órgãos acometidos tanto em humanos como em cães portadores do parasita em questão, causando nefropatia e, portanto merecendo atenção especial no estudo da doença (COSTA, 2001).

Os valores bioquímicos quando interpretados corretamente fornecem importantes informações sobre o estado clínico do animal (GONZÁLES et al., 2010), rotineiramente usa-se para avaliar a função renal a mensuração da concentração plasmática de substâncias normalmente excretadas pelos rins, sendo a avaliação dos níveis de uréia e creatinina os testes mais comumente utilizados (LANIS et al., 2008). A disfunção renal aparece frequentemente em cães como resultado de glomerulonefrite por deposição de imunocomplexos (POLI et al., 1991), muitas vezes sendo a principal causa da morte de cães com leishmaniose (SILVA, 2007). Ciaramella et al. (1997) relataram ainda que insuficiência renal pode estar presente em cães sem os sinais clínicos sistêmicos de leishmaniose.

Assim, torna-se importante o conhecimento dos níveis séricos de uréia e creatinina em cães naturalmente infectados com Leishmania e sua correlação com a sintomatologia do animal.

\section{MATERIAL E MÉTODOS}

Utilizou-se 44 cães provenientes do Centro de Controle de Zoonoses de Uberlândia - MG, sororreagentes para leishmaniose nos testes de Imunofluorêscencia Indireta (RIFI) e ELISA, ambos preconizados pelo Ministério da Saúde. Os cães foram avaliados clinicamente, conforme a ficha clínica do Hospital Veterinário da Universidade Federal de Uberlândia (HV-UFU) e após exame clínico realizou-se coleta de sangue.

Segundo Mancianti et al. (1988) os cães foram classificados em três grupos: assintomáticos (sem sinais clínicos); oligossintomáticos (um a três sinais clínicos) e sintomáticos (mais de três sinais clínicos), sendo que os principais sinais clínicos considerados para a divisão dos grupos foram: 
SOUSA, M.V.C. et al. Níveis séricos de uréia e creatinina em cães naturalmente infectados por Leishmania chagasi. PUBVET, Londrina, V. 5, N. 12, Ed. 159, Art. 1078, 2011.

onicogrifose, áreas de alopecia, linfadenomegalia, hepatoesplenomegalia e uveíte.

O sangue foi coletado por venopunção jugular, utilizando adaptador para coleta de sangue $\left(\right.$ Vacutainer $\left.^{\circledR}\right)$, agulha descartável e tubos sem anticoagulante $\left(\mathrm{BD}^{\circledR}\right)$. Após a coleta, o soro sanguíneo foi obtido no Laboratório Clínico Veterinário do HV-UFU por centrifugação a $720 \mathrm{~g}$ por 10 minutos. As dosagens séricas de uréia e creatinina foram realizadas utilizando kits comercias de avaliação $\left(\right.$ LabTest $\left.^{\circledR}\right)$ e mensuradas por analisador automático (Chemwell ${ }^{\circledR}$ ).

Considerou-se como normais os valores de uréia e creatinina variando de 21 a $60 \mathrm{mg} / \mathrm{dl}$ e 0,5 a 1,5 mg/dl, respectivamente, segundo Kaneko (1997).

A análise estatística foi feita pelas médias dos três grupos comparadas pelo teste de SNK (Student-Newman-Keuls Multiple Comparisons Test) e adotou-se como análise significativa quando o $\mathrm{P}<0,05$. $\mathrm{O}$ programa utilizado para obter-se a análise foi Graphpad Instat 3.0.

\section{RESULTADOS E DISCUSSÃO}

Reis et al. (2006) ao classificarem 40 cães infectados com Leishmania infantum obtiveram $12(30,0 \%)$ cães assintomáticos, $12 \quad(30,0 \%)$ oligossintomáticos e $16(40,0 \%)$ sintomáticos, já Costa et al. (2003) ao classificar 55 animais sororreagentes para leishmania, obtiveram $13(23,63 \%)$ cães assintomáticos $33(60,0 \%)$ sintomáticos e 9 (16,36\%) oligossintomáticos. Abreu-Silva et al. (2008) classificando 33 cães sororreagentes para leishmaniose verificaram 18 cães (56,25\%) sintomáticos; nove $(28,12 \%)$ assintomáticos e seis $(18,75 \%)$ oligossintomáticos. Seguindo os autores citados anteriormente a maior frequência de cães com leishmaniose são de cães sintomáticos o que difere do presente estudo que observou-se 23 $(52,27 \%)$ cães oligossintomáticos, 17 (38,63\%) sintomáticos e quatro $(9,09 \%)$ assintomáticos. O pequeno número de cães assintomáticos demonstra que 
esses cães são de difícil deteç̧ão e continuam representando um grande risco a saúde pública.

Os níveis de uréia variaram de $12 \mathrm{mg} / \mathrm{dl}$ a 479,6 mg/dl no grupo de animais sintomáticos, sendo a média 76,45 . Os oligossintomáticos apresentaram valores entre $14,5 \mathrm{mg} / \mathrm{dl}$ e $120,9 \mathrm{mg} / \mathrm{dl}$ com média 41,50 e os assintomáticos $10,9 \mathrm{mg} / \mathrm{dl}$ a $38,5 \mathrm{mg} / \mathrm{dl}$ com média 28,35 . Não obteve-se diferença entre os grupos $(p=0,2976)$ (Tabela 1).

O valor médio de creatinina para o grupo de animais sintomáticos foi de 1,37 , variando de $0,4 \mathrm{mg} / \mathrm{dl}$ a $4,98 \mathrm{mg} / \mathrm{dl}$. Já para o grupo oligossintomático a média foi de 0,99 variando de $0,48 \mathrm{mg} / \mathrm{dl}$ a $1,82 \mathrm{mg} / \mathrm{dl}$ e para os assintomáticos a média foi de 0,715 variando de $0,59 \mathrm{mg} / \mathrm{dl}$ a $0,81 \mathrm{mg} / \mathrm{dl}$ (Tabela 1). Também não obteve-se diferença estatística entre os grupos ( $p=$ $0,2637)$.

Tabela 1. Valores médios de uréia e creatinina em cães naturalmente infectados por Leishmania chagasi, Uberlândia- MG, 2010.

\begin{tabular}{ccc}
\hline Grupo & Uréia (DP) & Creatinina (DP) \\
\hline Sintomáticos & $76,45(119,17)$ & $1,37(1,36)$ \\
Oligossintomáticos & $41,50(26,29)$ & $0.99(0,31)$ \\
Assintomáticos & $28,35(12,24)$ & $0,71(0,09)$ \\
\hline P valor & $\mathbf{0 , 2 9 7 6}$ & $\mathbf{0 , 2 6 3 7}$
\end{tabular}

$\overline{\mathrm{DP}}=$ Desvio Padrão

Dias $(2008)^{a}$ ao realizar a análise estatística das médias de uréia e creatinina de 27 animais, sendo 14 sintomáticos e 13 assintomáticos também não obteve diferença estatística entre eles. Ao analisar os parâmetros bioquímicos de uréia e creatinina de 28 cães sororreagentes para leishmaniose, sendo 15 assintomáticos e 13 sintomáticos, Dias et al. (2008) observaram $22,72 \%$ de níveis de uréia aumentados e nenhum de creatinina. Do mesmo modo, Abreu-Silva et al. (2008) observou alteração renal após 
SOUSA, M.V.C. et al. Níveis séricos de uréia e creatinina em cães naturalmente infectados por Leishmania chagasi. PUBVET, Londrina, V. 5, N. 12, Ed. 159, Art. 1078, 2011.

terem verificado aumento na média dos valores da uréia, porém não observaram o mesmo em relação à creatinina.

$\mathrm{Na}$ insuficiência renal sugere-se que os sinais clínicos podem ser melhores correlacionados com o nível de uréia do que com o de creatinina, sendo que está provavelmente relaciona-se com a taxa de filtração glomerular, já que a excreção de uréia não depende somente desse fator mas também da taxa de fluxo do filtrado (FINCO, 1995).

Dos 17 animais sintomáticos obteve-se 7 (41,17\%) com níveis diminuídos de uréia, $6(35,29 \%)$ com níveis normais e 4 (23,52\%) com níveis aumentados. Quatro (17,39\%) animais oligossintomáticos $(n=23)$ apresentaram níveis de uréia diminuídos, 3 (13,04\%) aumentados e 16 $(69,56 \%)$ estavam com níveis normais.

Já em relação aos animais assintomáticos $(n=4)$ três $(75 \%)$ apresentavam níveis normais e um (25\%) níveis diminuídos (Tabela 2 ).

Tabela 2. Número de animais com concentração sérica de uréia aumentada, diminuída ou normal, de acordo com a sintomatologia clínica, Uberlândia - MG, 2010.

\begin{tabular}{lccc}
\hline $\begin{array}{l}\text { GrupoN. } \\
\text { Uréia }\end{array}$ & Sintomáticos & Oligossintomáticos Assintomáticos \\
\hline Diminuído & 7 & 4 & 1 \\
Aumentado & 4 & 3 & 0 \\
Normal & 6 & 16 & 3 \\
\hline Total & $\mathbf{1 7}$ & $\mathbf{2 3}$ & $\mathbf{4}$ \\
\hline
\end{tabular}

N. Uréia= Níveis de Uréia

Dos animais sintomáticos $11(64,70 \%)$ apresentaram níveis normais de creatinina, quatro $(23,52 \%)$ níveis aumentados e dois $(11,76 \%)$ níveis diminuídos. Entre os cães oligossintomáticos um (4,34\%) apresentou nível diminuído, 21 (91,30\%) estavam com níveis de creatinina normais e somente um aumentado $(4,34 \%)$ animal respectivamente. Já em relação ao grupo 
SOUSA, M.V.C. et al. Níveis séricos de uréia e creatinina em cães naturalmente infectados por Leishmania chagasi. PUBVET, Londrina, V. 5, N. 12, Ed. 159, Art. 1078, 2011.

assintomático todos os animais apresentaram níveis normais de creatinina (Tabela 3).

Tabela 3. Número de animais com concentração sérica de creatinina aumentada, diminuída ou normal, de acordo com a sintomatologia clínica, Uberlândia - MG, 2010.

\begin{tabular}{lccc}
$\begin{array}{l}\text { Grupo N. } \\
\text { Uréia }\end{array}$ & Sintomáticos & Oligossintomáticos Assintomáticos \\
\hline Diminuído & 2 & 1 & 0 \\
Aumentado & 4 & 1 & 0 \\
Normal & 11 & 21 & 4 \\
\hline Total & $\mathbf{1 7}$ & $\mathbf{2 3}$ & $\mathbf{4}$ \\
\hline
\end{tabular}

\section{N. Uréia = Níveis de Uréia}

Os animais oligossintomáticos, assim como os assintomáticos, não apresentaram em sua maioria níveis aumentados de uréia e creatinina. Pelo caráter crônico da enfermidade, espera-se que os animais somente manifestem alterações renais após a instalação da doença e deposição dos imunocomplexos, obedecendo ao curso natural da doença. Porém, os animais sintomáticos também não apresentaram em sua maioria níveis aumentados de uréia e creatinina, demonstrando a variabilidade na manifestação clínica desta doença o que dificulta ainda mais o seu diagnóstico e a padronização dos seus sinais clínicos.

Os rins são comumente acometidos por cães com leishmaniose (CIARAMELLA, et al., 1997) e como já foi dito a deposição de imunocomplexos leva há uma glomerulonefrite e nefrite instersticial e consequentemente uma insuficiência renal (FEITOSA, et al., 2000), que pode levar a uma proteinúria, hematúria e ao aumento dos níveis de uréia e creatinina (ETTINGER, 1997). Em estágios mais avançados da leishmaniose este aumento pode ocorrer, porém o número de casos é relativamente baixo (AMUSATEGUI et al. 2003). 
SOUSA, M.V.C. et al. Níveis séricos de uréia e creatinina em cães naturalmente infectados por Leishmania chagasi. PUBVET, Londrina, V. 5, N. 12, Ed. 159, Art. 1078, 2011.

Nieto et al. (1992) cita que é mais comum ocorrer aumento nos níveis de uréia do que de creatinina em cães com leishmania. Kiral, et al. (2006) utilizando 10 cães infectados experimentalmente com Leishmania infantum, avaliaram que os níveis de uréia não apresentaram-se alterados, porém houve um aumento significativo nos valores de creatinina indicando que houve um comprometimento renal.

\section{Conclusão}

Considerando a classificação dos cães naturalmente infectados com leishmania em assintomáticos, oligossintomáticos e sintomáticos, não tem relevância à associação entre estes grupos e o aumento nos níveis séricos de uréia e creatinina, pois nem sempre um animal sintomático apresentará esta alteração laboratorial.

\section{Referências}

ABREU-SILVA, A. L.; LIMA, T. B.; DE MACEDO, A.A.; MORAES-JÚNIOR, F. J.; DIAS, E. L.; BATISTA, Z. S.; CALABRESE, K. S.; MORAES, J. L. P.; REBÊLO, J. M. M.; GUERRA, R. M. S. N. C. Soroprevalência, aspectos clínicos e bioquímicos da infecção por Leishmania em cães naturalmente infectados e fauna de flebotomíneos em uma área endêmica na Ilha de São Luís, Maranhão, Revista Brasileira de Parasitologia Veterinária, v.17, Supl. 1, 197-203, 2008.

AMUSATEGUI, I.; SAINZ, A.; RODRIGUEZ, F.; TESOURO, M.A. Distribution and relationships between clinical and biopathological parameters in canine leishmaniasis. European Journal of Epidemiology, v.18, p. 147-156, 2003.

BRASIL. Ministério da Saúde, Boletim eletrônico epidemiológico - ANO 03 - No 05 - Uberaba, MG, 12/12/2003, Disponível em: http://portalsaúde.gov.br /portal/arquivos/pdf/boletim_eletronico_05_ano03.pdf. Acessado em: 26/10/10.

CIARAMELLA, P.; OLIVA, G.; LUNA, R.; AMBROSIO, R.; CORTESE, L.; PERSECHINO, A.; GRADONI, L.; SCALONI, A. A retrospective clinical study of canine leishmaniasis in 150 dogs naturally infected by Leishmania infantum. The Veterinary Record, v.141, p.539-543, 1997.

COSTA, F. A. L.; GOTO, H.; SALDANHA, L. C. B.; SILVA, S. M. M. S.; SINHORINI, I. L.; SILVA, T. C.; GUERRA, J. L. Histopathologic Patterns of Nephropathy in Naturally Acquired Canine Visceral Leishmaniasis. Veterinary Pathology, v. 40, p. 677- 684, 2003.

COSTA, F. A. L. Patologia e imunopatologia da nefropatia da leishmaniose visceral canina. São Paulo: USP, Faculdade de Medicina Veterinária e Zootecnia, Tese (Tese em Medicina Veterinária). p. 129, 2001. 
SOUSA, M.V.C. et al. Níveis séricos de uréia e creatinina em cães naturalmente infectados por Leishmania chagasi. PUBVET, Londrina, V. 5, N. 12, Ed. 159, Art. 1078, 2011.

DA SILVA, S. M.; RIBEIRO, V. M.; RIBEIRO, R. R.; TAFURI, W/L.; MELO, M. M.; MICHALICK. First report of vertical transmission of Leishmania (Leishmania) infantum in a naturally infected bitch from Brazil. Veterinary Parasitology, March, v. 10. p. 1016, 2009.

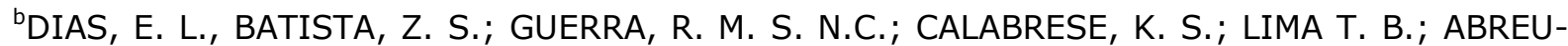
SILVA, A. L. Canine Visceral Leishmaniasis (CVL): Seroprevalence Clinica, hematological and biochemical, findings of dogs naturally infected in na endemic área of São José de Ribamar municipality, Maranhão State, Brazil. Ciência Animal Brasileira, v. 9, n. 3, p. 740-745, 2008.

${ }^{a}$ DIAS, C. A. Estudo das alterações clínico laboratoriais e histopatológicas renais em cães com leishmaniose visceral naturalmente infectados no Distrito Federal. Brasília. 2008, 82 p. Dissertação (Mestrado em Saúde Animal) - Curso de pós graduação em Faculdade de Agronomia e Medicina Veterinária, Universidade de Brasília.

ETTINGER, S. J., FELDMAN, E. C. Tratado de Medicina Interna Veterinária: moléstia de cão e do gato. 4a ed. São Paulo: Manole, v.2, p.3020, 1997.

FEITOSA, M.M.; IKEDA, F. A.; LUVIZOTTO, M. C.; PERRI, S.H.V. Aspectos clínicos de cães com leishmaniose visceral no município de Araçatuba - São Paulo (Brasil). Clínica Veterinária, n.28, p. 36-44, 2000.

FINCO, D. R. Evaluation of renal functions. In: OSBORNE, C. A.; FINCO, D. R. Canine and feline nephrology and urology. Filadelfia: Lippincott Willians \& Wilkins, 1995. cap.10. p.216-228.

GONZÁLEZ F. H. D.; CARVALHO V.; MÖLLER V. A.; DUARTE F. R. Perfil bioquímico sangüíneo de cães e gatos na cidade de Porto Alegre, Rio Grande do Sul, Brasil. Arquivo da Faculdade de Veterinária da UFRGS. v. 29, p.1-6. 2001.

KANEKO, J. J.; HARVEY, J. W.; BRUSS, M. L. (eds.) Clinical biochemistry of domestic animals. 5th ed. New York: Academic Press, 1997.

KIRAL, F. K.; SEYREK, K.; PASA, S.; ERTABAKLAR, H.; ÜNSAL, C. Some Haematological, Biochemical and Electrophoretic Findings in Dogs with Visceral Leishmaniasis. Revue de Médecine Vétérinaire, v. 4, p. 226-229, 2004.

LANIS, A.B.; FONSECA, L.A.; ROESLER, T.; ALFES, A.; LOPES, B. Avaliação laboratorial das doenças renais em pequenos animais. Pubvet, v. 2, n. 28, 2008.

LOPEZ, R.; LUCENA, R.; NOVALES, M.; GINEL, P.J.; MARTIN, E.; MOLLEDA, M. Circulating immune complexes and renal function in canine leishmaniasis. Journal

of Veterinary Medicine, v. 43, p. 469-474, 1996.

MACHADO, J. G.; HOFFMANN, J. L.; LANGONI, H. Imunopatologia da leishmaniose visceral canina. In: Saúde Pública. Clínica Veterinária, p.50-57, 2007.

MANCIANTI, F.; GRAMICCIA, M.; GRADONI, L.; PIERI, S. Studies on canine control. Evolution of infection of different clinical forms of canine leishmaniasis following antimonial treatment. Transactions of the Royal Society of Tropical Medicine and Hygiene, v. 82, p. 566-567, 1988.

NIETO, C. G.; NAVARRETE, I.; HABELA, M. A. et al. Pathological changes in Kidneys of dogs with natural leishmania infection. Veterinary Parasitology., v.45, n.1-2, p. 33-47, 1992. 
SOUSA, M.V.C. et al. Níveis séricos de uréia e creatinina em cães naturalmente infectados por Leishmania chagasi. PUBVET, Londrina, V. 5, N. 12, Ed. 159, Art. 1078, 2011.

OLIVEIRA, M.F.S.T.; MINEO, T. W. P.; BASON, M.; DAY, M. J.; MACHADO, R. Z. IgG subclass prole of serum antibodies to Leishmania chagasi in naturally infected and vaccinated dogs. Veterinary Parasitology, p. 16-22. February, 2009.

POLI A., ABRAMA F., MANCIANTI F., NIGRO M., PIERI S. and BIONDO A. : Renal involvement in canine leishmaniasis. Nephron, 57, 44-452. 1991.

REIS, A.B.; MARTINS - FILHO. O. A.; TEIXIERA- CARVALHO, A.;CARVALHO, M. G.; MAYRINK, W.; FRANÇA-SILVA, J. C.; GENARO, O.; CORRÊA- OLIVEIRA, R. Parasite density and impaired biochemical / hematological status are associated with severe clinical aspects of canine visceral leishmaniasis. Research in Veterinary Science, v. 81, n. 1, p. 68-75, 2006.

SILVA, F. S. Patologia e patogênese da leishmaniose visceral canina Revista Tropical Ciências Agrárias e Biológicas, v.1, n. 1, p. 20, 2007. 